\title{
The Structural Characterization of Ni-Ti-Zr Metallic Glass
}

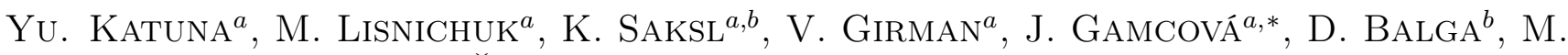 \\ D̆URIŠIN $^{b}$, J. KOVÁČ ${ }^{c}$ AND P. SOVÁK ${ }^{a}$ \\ ${ }^{a}$ Institute of Physics, Faculty of Science, P.J. Šafárik University, Park Angelinum 9, 04154 Košice, Slovakia \\ ${ }^{b}$ Institute of Materials Research, Slovak Academy of Sciences, Watsonová 47, 04001 Košice, Slovakia \\ ${ }^{c}$ Institute of Experimental Physics, SAS, Watsonová 47, 04001 Košice, Slovakia
}

\begin{abstract}
Metallic glasses, in contrast to its crystalline counterparts, exhibit unique mechanical and structural properties, which make them attractive for practical applications. Especially $\mathrm{Ni}-\mathrm{Ti}-\mathrm{Zr}$ metallic glass is a promising alloy for micromechanical systems because of its known shape memory properties. Shape memory effect is connected with structural phase transformation. In this paper, the ambient-temperature-structure of $\mathrm{Ni}-\mathrm{Ti}-\mathrm{Zr}$ metallic glass is investigated using transmission electron microscopy and synchrotron X-ray diffraction, the surface and chemical analysis is documented using scanning electron microscopy. Thermal stability of the alloy has been determined using differential scanning calorimetry.
\end{abstract}

DOI: $10.12693 /$ APhysPolA.131.750

PACS/topics: 75.50.Kj, 68.37.Ma, 68.37.Lp

\section{Introduction}

Shape memory alloys (SMA) belong to smart materials with capability of recovery its original shape by heating after high degree of deformation. $\mathrm{Ni}-\mathrm{Ti}-\mathrm{Zr}$ is seen as one of the most promising high-temperature SMAs. This alloy has many positive characteristics of the binary system and also significantly increases martensiteto-austenite transformation temperature, which can be controlled with the $\mathrm{Zr}$ content [1-3]. $\mathrm{Ni}-\mathrm{Ti}$ is well known SMA and has suitable mechanical properties, corrosion resistance and biocompatibility [4]. Since the shape memory effect is manifested only in crystalline materials, our goal was to produce and investigate amorphous precursor material, from which reliable shape memory material with interesting mechanical properties will be prepared later.

\section{Material preparation}

For preparation of the master alloy, elements of high purity are needed in order to avoid formation of unwanted phases, e.g. oxides, and/or intermetallic. For preparation of the master alloy, elements of purity $99.9 \%$ were used.

The powder material was compressed by press machine to the tablet form, which suppresses material losses during subsequential arc-melting. For master alloy preparation, Mini Arc Melting System MAM-1 was used. The sample has been re-melted 3 times in order to ensure homogeneous elements distribution within the entire volume of alloy. The resulting master alloy had lens-like shape. For the preparation of ribbon with composition of $\mathrm{Ni}_{60} \mathrm{Ti}_{25} \mathrm{Zr}_{15}$ at.\% alloy Melt Spinner SC was used. The final ribbon has thickness of $60 \mu \mathrm{m}$ and width of $4 \mathrm{~mm}$. The melting point of $\mathrm{Ni}_{60} \mathrm{Ti}_{25} \mathrm{Zr}_{15}$ has been estimated to be $1657 \mathrm{~K}$.

*corresponding author; e-mail: jana.gamcova@upjs.sk
Differential scanning calorimetry (DSC) is a method commonly used for determining the thermal stability characteristics of amorphous alloys. DSC measurements was performed using the Perkin Elmer DSC 8000 under argon atmosphere with heating rate $10 \mathrm{~K} / \mathrm{min}$.

\section{Experimental part}

Figure 1 shows DSC curve of the as-quenched alloy measured at heating rate $10 \mathrm{~K} / \mathrm{min}$. It exhibits one endothermic event and three exothermic peaks as a characteristic feature for amorphous materials.

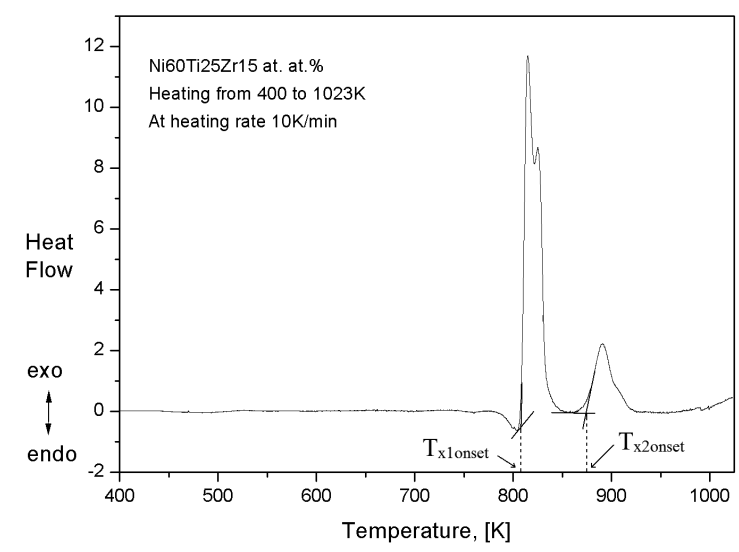

Fig. 1. DSC curve obtained at constant heating rate of $10 \mathrm{~K} / \mathrm{min}$.

The glass transition temperature $\left(T_{g}\right)$ represented by endothermic event is at $790 \mathrm{~K}$. The first observable crystallization starts at temperature $T_{x 1 \text { onset }}=$ $807 \mathrm{~K}$. The second crystallization starts at temperature $T_{x 2 \text { onset }}=875 \mathrm{~K}$. The third crystallisation starts at $T_{x 3 \text { onset }}=1003 \mathrm{~K}$. The super-cooled liquid region calculated as $\Delta T=T_{x 1 \text { onset }}-T_{g}$ is $17 \mathrm{~K}$ wide for the applied heating rate. 
By heating the as-quenched alloy to crystallisation temperatures, the sample becomes crystalline having significantly different properties. In the associated paper [5] the structural and magnetic properties were investigated. Based on DSC results the as-quenched state as well as samples heated to $T_{x 1}, T_{x 1 \text { out }}, T_{x 2}, T_{x 2 \text { out }}$ and $T_{x 3}$ were chosen (Table I).

\section{TABLE I}

Significant temperatures of the $\mathrm{Ni}_{60} \mathrm{Ti}_{25} \mathrm{Zr}_{15}$ amorphous alloy obtained at constant heating rate of $10 \mathrm{~K} / \mathrm{min}$.

\begin{tabular}{c|c|c|c}
\hline \hline$T_{g}[\mathrm{~K}]$ & 790 & $T_{x 2}[\mathrm{~K}]$ & 890 \\
\hline$T_{x 1 \text { onset }}[\mathrm{K}]$ & 807 & $T_{x 2 \text { out }}[\mathrm{K}]$ & 914 \\
\hline$T_{x 1}[\mathrm{~K}]$ & 814 & $T_{x 3 \text { onset }}[\mathrm{K}]$ & 1003 \\
\hline$T_{x 1 \text { out }}[\mathrm{K}]$ & 837 & $T_{x 3}[\mathrm{~K}]$ & 1023 \\
\hline$T_{x \text { 2onset }}[\mathrm{K}]$ & 875 & $\Delta T[\mathrm{~K}]$ & 17
\end{tabular}

For the study of ribbon surfaces, the scanning electron microscope (SEM) Tescan Vega-3 XMU was used. Accelerating voltage was set on $20 \mathrm{keV}$ with respect to detected elements in regime of secondary electrons. Imaging in secondary electrons and energy-dispersive $\mathrm{X}$ ray spectroscopy (EDS) spectrum of the alloy free surface (Fig. 2a), wheel surface (Fig. 2b) and cross-section (Fig. 3a) were done.

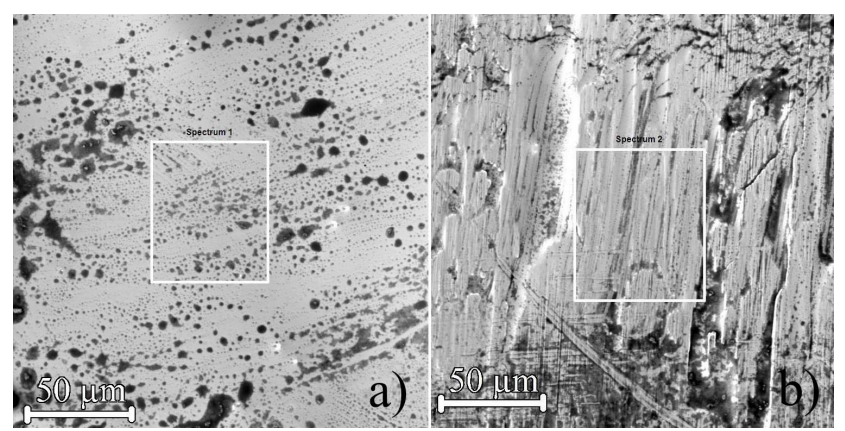

Fig. 2. (a) SEM image of $\mathrm{Ni}_{60} \mathrm{Ti}_{25} \mathrm{Zr}_{15}$ free surface. (b) SEM image of $\mathrm{Ni}_{60} \mathrm{Ti}_{25} \mathrm{Zr}_{15}$ wheel surface.

From the EDS analysis, it is evident that prepared sample is consistent with the intended composition (Table II).

TABLE II

EDS analysis of $\mathrm{Ni}_{60} \mathrm{Ti}_{25} \mathrm{Zr}_{15}$ alloy surface.

\begin{tabular}{c|c|c|c|c}
\hline \hline Area & $\mathrm{Ti}$ & $\mathrm{Ni}$ & $\mathrm{Zr}$ & Total \\
\hline free (Fig. 2a) & 27.31 & 58.04 & 14.66 & 100.00 \\
wheel (Fig. 2b) & 27.42 & 57.39 & 15.19 & 100.00
\end{tabular}

Chemical composition across the sample was verified by line EDS analysis, and it can be concluded that the sample is completely homogeneous over the sample thickness (Fig. 4). From the images, we can also estimate that the thickness of the ribbon is $\approx 60 \mu \mathrm{m}$ (Fig. 3b).
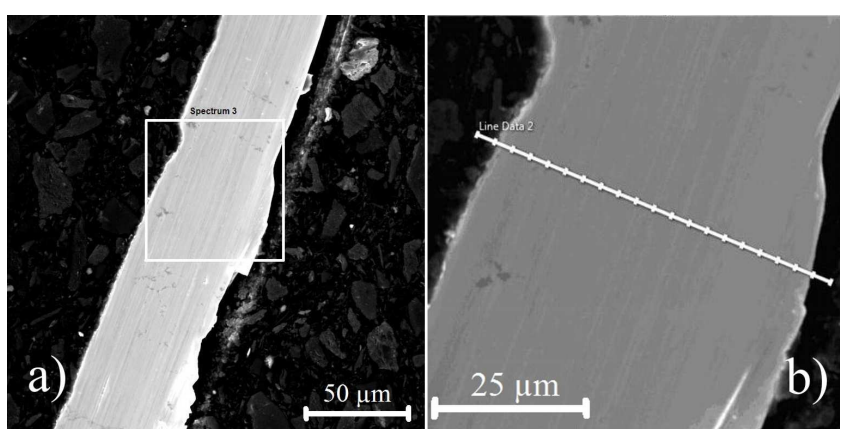

Fig. 3. (a) SEM image of $\mathrm{Ni}_{60} \mathrm{Ti}_{25} \mathrm{Zr}_{15}$ cross-section, (b) depicted line for EDS line profiles acquisition of $\mathrm{Ni}_{60} \mathrm{Ti}_{25} \mathrm{Zr}_{15}$ ribbon in cross-section.

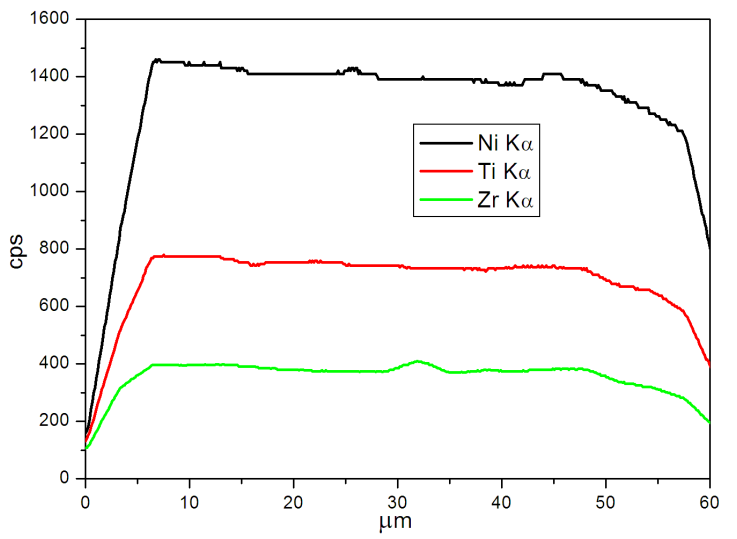

Fig. 4. Line profiles of measured EDS spectra of $\mathrm{Ni}_{60} \mathrm{Ti}_{25} \mathrm{Zr}_{15}$ cross-section.

The structural state of the prepared as-quenched alloy has been examined also by transmission electron microscopy (TEM) JEOL JEM 2100F UHR equipped by Schottky FEG cathode. Applied accelerating voltage was $200 \mathrm{kV}$. Both, the image and the selected area diffraction pattern were taken in order to determine the amorphous/crystalline nature of as-quenched $\mathrm{Ni}_{60} \mathrm{Ti}_{25} \mathrm{Zr}_{15}$ alloy (Fig. 5). The imaged structure does not reveal presence of any nanocrystals and confirms fully amorphous phase. Embedded electron diffraction pattern taken from the selected area shows typical diffuse rings and also confirms amorphous nature of the investigated sample. Even on diffraction pattern there is no indication of any crystalline phase present.

Experimental measurements of the phase composition of the alloy were examined using X-ray diffraction at the synchrotron radiation sources in Deutsches Elektronen Synchrotron - DESY (Germany, Hamburg). The results of processed synchrotron XRD data are shown in Fig. 6. Obtained diffraction profile also confirms fully amorphous nature of $\mathrm{Ni}_{60} \mathrm{Ti}_{25} \mathrm{Zr}_{15}$ alloy.

\section{Conclusions}

1. The DSC curve of the alloy shows three distinctive exothermic peaks corresponding to different phase transi- 


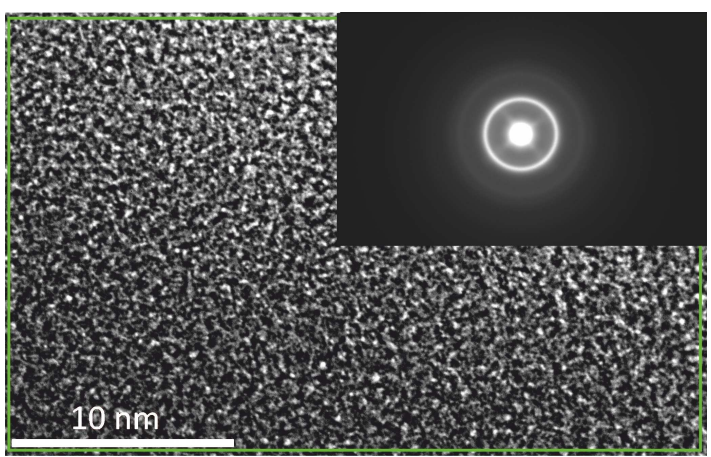

Fig. 5. Bright-field TEM image and diffraction pattern of $\mathrm{Ni}_{60} \mathrm{Ti}_{25} \mathrm{Zr}_{15}$ melt-spun ribbons.

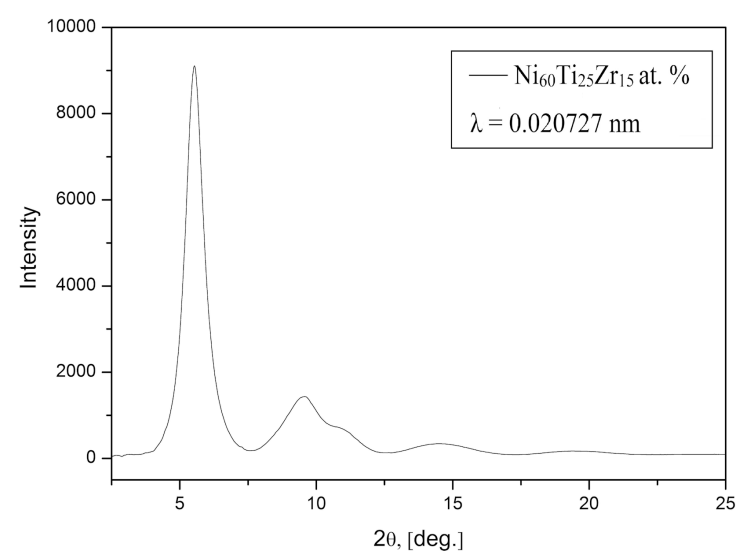

Fig. 6. XRD patterns of $\mathrm{Ni}_{60} \mathrm{Ti}_{25} \mathrm{Zr}_{15}$.

tions of the alloy. The DSC curve shows one-endothermic three exothermic events. The endothermic event corresponds to glass transition temperature $\left(T_{g}\right)$ and it was determined at $790 \mathrm{~K}$. The first, the second, and the third observable crystallizations start at the temperatures 807 , 875 , and $1073 \mathrm{~K}$, respectively. Super cooled liquid region width is $17 \mathrm{~K}$.

2. TEM, DSC, and XRD analyses proved that asquenched sample $\mathrm{Ni}_{60} \mathrm{Ti}_{25} \mathrm{Zr}_{15}$ is fully amorphous.

3. Examined chemical composition was confirmed by point EDS analysis and by line EDS analysis across the edge. The sample exhibits acceptable grade of homogeneity.

4. In the related paper [5] saturation magnetization measurements of the sample depending on temperature was performed, during which segregation of pure nickel from solid structure was noticed. The most appropriate explanation of this peculiar phenomenon is the superposition of several effects. The first one is the decomposition of structure well-known from $\mathrm{Ni}-\mathrm{Ti}$ shape memory alloy [6] via precipitation of Ni-rich particles. The second, with the decrease of mixing enthalpy $\Delta H^{m i x}$, the tendency towards formation of intermetallic phase is increasing, and if we consider negative $\Delta H^{m i x}$ of $\mathrm{Ni}-\mathrm{Ti}$ and $\mathrm{Ni}-\mathrm{Zr}$ pairs, the precipitation of Ni-reach particles should be more understandable. However, pure nickel separation may be caused by the third effect. $\Delta H^{\text {mix }}$ for $\mathrm{Ti}-\mathrm{Zr}$ pair is equal to $0 \mathrm{~kJ} / \mathrm{mol}$, which means that $\mathrm{Ti}-\mathrm{Zr}$ has great potential to create simple solid solution with complete mutual solubility in solid state. The formation of the $\mathrm{Ti}-\mathrm{Zr}$ solid solution is also encouraged by the same hexagonal lattice of both elements and small difference in electronegativity. According to all that, we assume the $\mathrm{Ni}-\mathrm{Ti}-\mathrm{Zr}$ alloy decreases its overall volume energy by separation of $\mathrm{Ti}-\mathrm{Zr}$ atoms from the structure, forming its solid solution and changing nickel paramagnetic state into ferromagnetic.

\section{Acknowledgments}

This work was supported by the project VEGA $1 / 0036 / 16$. This work was realized within the frame of the project NanoCEXmat II (ITMS 26220120035) "Infrastructure Improving of Centre of Excellence of Advanced Materials with Nano- and Submicron Structure", which is supported by the Operational Program "Research and Development" financed through European Regional Development Fund.

\section{References}

[1] S.F. Hsieh, S.K Wu, J. Mater. Character. 41, 151 (1998).

[2] S.F. Hsieh, S.K Wu, J. Alloys Comp. 266, 276 (1998).

[3] P.J. McCluskey, J.J. Vlassak, J. Mater. Res. 25, 2086 (2010)

[4] K. Otsuka, X. Ren, J. Prog. Mater. Sci. 50, 511 (2005).

[5] M. Lisnichuk, Yu. Katuna, K. Saksl, V. Girman, J. Gamcová, D. Balga, M. Duurišin, J. Kováč, P. Kollár, P. Sovák, Acta Phys. Pol. A 131, 741 (2017).

[6] M. Kuběnová, Ph.D. Thesis, 2014. 